\title{
STUDENTS' ABILITY IN USING DISCOURSE MARKERS TO BUILD COHERENCE IN COMPOSITIONS
}

\author{
Andhina W. Patriana \\ (andhina.patriana@gmail.com) \\ Sri Rachmajanti \\ (loekisr@gmail.com) \\ Nur Mukminatien \\ (nursunaryo@gmail.com) \\ Universitas Negeri Malang, Indonesia \\ Jl. Semarang 5, Malang
}

\begin{abstract}
The study attempts to find out how Indonesian students apply Discourse Markers (DMs) to build coherence in English compositions. It employs a descriptive design, analyzing 52 target DMs and how they are used in 21 argumentative papers. The participants of the study were 21 Master's students majoring in English Language Teaching (ELT). The results reveal that the participants employ 44 DMs in 234 occurrences, and use some DMs inappropriately in 118 occurrences. The problematic matters cover: non-equivalent exchange, overuse, surface logic, misinterpreted relation, and mistranslation. The study concludes that although the participants have shown their awareness of using DMs to build coherent compositions, there are areas where improvement is needed to increase their ability in using DMs appropriately and effectively to make their writing better and more logically connected. Recommendations to English teachers are also given as pedagogical implications of this study.
\end{abstract}

Keywords: discourse markers, coherence, cohesion, argumentative essays.

DOI: http://dx.doi.org/10.15639/teflinjournal.v27i2/203-216 
Coherence and cohesion are two indispensable aspects in a good writing, including but not limited to writing in English as a second language (L2 writing). A text is coherent if it makes sense and its elements connect one another by the use of cohesive devices such as referents, substitutions, ellipsis, conjunctions, and lexical cohesions (Halliday \& Hasan, 1976). In writing beyond sentence level, however, using cohesive devices only is not enough to make the text coherent. According to Schiffrin (1987), Tyler and Bro (1992), and Muller (2004), the presence of discourse markers (e.g. however, accordingly, for example) can contribute to the coherence of a text in the same way as cohesive devices do.

Although it has long been a subject of research, there is no universal term and definition for DM yet. One of the most influential definitions is from Fra$\operatorname{ser}(1999$, p. 931).

“... a class of lexical expressions drawn primarily from a class of conjunctions, adverbs and prepositional phrases and with certain exceptions they signal a relationship between the interpretations of the segment they introduce S1 and the prior segment S2. They have core meaning which is procedural, not conceptual, and their more specific interpretation is 'negotiated' by the context, both linguistic and conceptual."

In his definition, Fraser (1999) elaborates that DM encodes a semantic relationship between units of discourse without changing the semantic relation between them. Based on his definition, DM in this study is defined as a word or a phrase, a conjunction, an adverbial or prepositional phrase that can be used to signal a relationship between the segment they introduce and the previous segments.

As far as writing is concerned, the appropriate use of DMs helps the writer produce an effective text. The presence of DMs in written discourse is similar to things as gestures or non-verbal language in spoken discourse; showing the writer's awareness in organizing the text by marking the development of their argument and guiding the readers towards the writer's preferred interpretations (Biber, Johansson, Leech, Conrad \& Finegan, 1999; Celce-Murcia \& LarsenFreeman, 1999). Insufficient knowledge and the inappropriate use of DMs may therefore cause difficulty in the coherence interpretation.

Despite its important role, many studies have shown that applying DMs is not an easy matter for second language (L2) learners of English (Cho, 1998; 
Bolton, Nelson \& Hung, 2002; Narita, Sato \& Sugiura, 2004). They report some problems encountered by L2 learners, such as misuse, overuse, and underuse of some DMs. Different from the mentioned studies, Kao and Chen (2011) propose six types of problem commonly encountered by Taiwanese students; they are non-equivalent exchange, overuse, surface logicality, wrong relation, semantic incompletion, and distraction.

The results of a preliminary study conducted by the researchers reveal that composing a coherent text is difficult to Indonesian students. It is not the grammaticality that makes writing become incoherent, but it is the organization and the relationship between ideas. The problems encountered by Indonesian students in using DMs can be categorized into: non-equivalent exchange, overuse, surface logic, misinterpreted relation, and mistranslation problem as summarized in Table 1.

Table 1. Problems with DMs

\begin{tabular}{ll}
\hline $\begin{array}{l}\text { Non-Equivalent Ex- } \\
\text { change }\end{array}$ & $\begin{array}{l}\text { DMs are used to convey the same textual relation in } \\
\text { an interchangeable manner when they are not. }\end{array}$ \\
\hline Overuse & $\begin{array}{l}\text { The context would be coherent in itself without the } \\
\text { use of the DMs or that the use is redundant. }\end{array}$ \\
\hline Surface Logic & $\begin{array}{l}\text { DMs are applied to impose logicality to texts or } \\
\text { bridge the gap among propositions when there is no } \\
\text { deep logicality in texts. }\end{array}$ \\
\hline $\begin{array}{l}\text { Misinterpreted rela- } \\
\text { tion }\end{array}$ & $\begin{array}{l}\text { The connection represented by the DM does not cor- } \\
\text { respond to the relation that exists between sentences. }\end{array}$ \\
\hline Mistranslation & $\begin{array}{l}\text { The DMs used are derived from Indonesian-English } \\
\text { word-by-word translation, which does not match with } \\
\text { the intended meaning in English. }\end{array}$ \\
\hline
\end{tabular}

With regard to the previous research findings, the current study attempts to find out the extent to which the Indonesian students learning English use DMs to build coherence in compositions. Before describing the study in details, it needs to be noted that the use of DMs to link units of discourse above the sentence level in written discourse is the only variable examined in this study. Hence, the research problems in the study are: (1) What DMs do students use to build coherence in their compositions? (2) What problems do students encounter in using DMs in their compositions? 


\section{METHOD}

This is a descriptive study conducted at a Graduate Program in English Language Teaching. The participants are twenty-one (21) Master's (Magister Program) students of ELT from the $2^{\text {nd }}$ semester class. During the investigation, the participants were taking the Critical Review of Applied Linguistics (CRAL) course. The sources of the data are participants' CRAL papers of an argumentative genre.

The target DMs in the study are 52 DMs adapted from Fraser's (1999) and Halliday and Hasan's (1976) taxonomy of DMs. Given that some of the DMs are made on the basis of spoken discourse, some alterations are made so that it is applicable for the analysis of DMs in an academic writing context (see Table 2 ). The semantic relations are partly based on Parrot (2000), Quirk, Greenbaum, Leech and Swartvik (1985) and Merriam-Webster Dictionary and Thesaurus (2012).

Table 2. Taxonomy of DMs Adapted from Fraser's (1999) and Halliday and Hasan's (1976)

\begin{tabular}{ll}
\hline Elaborative Markers & $\begin{array}{l}\text { and, in addition, further, besides, additionally, more- } \\
\text { over, furthermore, similarly, likewise }\end{array}$ \\
\hline Additive Markers & otherwise, in other words, that is, in one word \\
\hline Appositive Markers & for example, for instance \\
\hline Illustration Markers & $\begin{array}{l}\text { in short, in sum, in brief, in summary, in conclusion, } \\
\text { to sum up }\end{array}$ \\
\hline Summative Markers & $\begin{array}{l}\text { but, however, nevertheless, nonetheless, yet, still, } \\
\text { though }\end{array}$ \\
\hline Adversative Markers & in fact, indeed, of course \\
\hline Concessive Markers & instead, on the contrary, rather \\
\hline Corroborative Markers & $\begin{array}{l}\text { on the other hand, in contrast, by contrast, conversely, } \\
\text { alternatively }\end{array}$ \\
\hline Corrective Markers & $\begin{array}{l}\text { thus, so, therefore, (in) this way, then, hence, in this } \\
\text { respect, in this case, consequently, as a result, as a } \\
\text { consequence, for this reason, accordingly. }\end{array}$ \\
\hline Causal-Inferential Markersers
\end{tabular}

In order to be classified as DMs, certain words and expressions must meet several criteria. Firstly, they must belong to one grammatical class: conjunc- 
tions, adverbs, or prepositional phrases. Secondly, they must link linguistic units above the sentence level. Thirdly, the withdrawal of the expression does not affect the grammaticality of the sentence. Lastly, they must perform the function to indicate logical relationship between the two segments they link.

The study involves some steps. The first step is extracting every word and expression that functions as DMs along with their adjacent sentences. The extracted DMs are coded, categorized, and analyzed to identify if they are used properly. To increase the credibility and validity of the results, a triangulation procedure is done by assigning a native speaker who has a Master's degree in TESOL to help the researcher examine the use of individual DM. In addition, there is also participants' verification, aiming to verify and confirm the researcher's interpretation as to why the participants apply such DMs in their writing.

\section{FINDINGS AND DISCUSSION}

This section presents the findings and discussion for each research problem. It is necessary to note that all of the examples here are excerpts extracted verbatim from the participants' compositions without any revision on grammatical errors.

\section{DMs Used by Indonesian ELT Students}

The findings show that the participants use 44 different DMs in 234 occurrences, 219 of which are used in the beginning of the sentences, and are always followed by a comma. This shows that participants tend to break a complex sentence into a simple one and simply add a DM at the beginning of the second segment to indicate a change of topic. Their use of DMs supports McCarthy's (1993) claim that a DM can constitute and extend the content of discourse better than a conjunction.

Based on DMs taxonomy adapted from Fraser (1999) and Halliday and Hasan (1976), the results of the study show that there are 234 occurrences of using DMs in the students' argumentative writing. The number of occurrences of each type of taxonomy is in Table 3.

Table 3 shows that there is high frequency for the use of both adversative and causal inferential markers. It is probably related to the nature of the argumentative text. Adversative markers have the highest frequency of occurrence for the participants to show the need in demonstrating their differences on 
some issues and to anticipate the opposite ideas from the reader's point of view and try to refute them. The presence of causal inferential markers is predicted for the participants as the need to establish evidence for argumentative claims. In addition, the participants' high-frequency use of additive and illustration markers demonstrates that they elaborate their ideas by giving additional information and showing examples.

Table 3. The DMs Category in the Students' Writing

\begin{tabular}{lc}
\hline \multicolumn{1}{c}{ Types } & Occurrences \\
\hline Adversative Markers & 85 \\
Causal Inferential Markers & 76 \\
Elaborative Markers & 73 \\
\hline
\end{tabular}

Unfortunately, not all adversative markers employed by the participants correspond to the relation between the segments. Often they use adversative markers in additive relations implying that Indonesian ELT students tend to organize their additional information in contrastive manners to achieve what is called argumentative writing. The following excerpts are the illustration of the use of DMs.

1) Many Chinese students were being investigated as they are claimed to have the largest English learning population (Cheng, 2001in Ong, 2011). *Nevertheless, Indonesia also has a large number of English learning populations since English has been taught since a very beginning level of education.

2) Mostly, students do mistakes on grammar (Subject-Verb agreement and Noun Phrase), misspelling the words (in the discussion focus on the adjective). *On the other hand, students' lack of vocabulary especially adjectives made them difficult to create longer descriptive paragraph.

In both excerpts, the participants use adversative markers nevertheless (example 1) and on the other hand (example 2) to connect segments which have additive relations instead of adversatives. In example 1, the subject is explaining the similarities between China and Indonesia in terms of the number of English learning population. The suitable marker to link the preceding and subsequent segments is similarly. In example 2, the subject is elaborating the errors that hinder students from composing a good writing. The error is not only on grammatical accuracy and spelling, but also on the use of vocabulary. Since 
the relation between these two segments is additive, the marker is best replaced with in addition.

The findings also show that the participants are still unable to differentiate between DMs and conjunctions. Some participants employ a subordinate conjunction (even though, while, whereas) in the place of DMs, making the sentence choppy and semantically inappropriate. The example is as follows.

3) Temporary teacher in private school tend to improve they professionalism because they have opportunity to progress their career if they have better achievement in teaching process. ${ }^{*}$ Eventhough, temporary teachers who teach in public school tend to be civil servant oriented because there is less attention from government about they career progression.

Example (3) demonstrates the subject's inability to differentiate between subordinate a conjunction and DM. He/she uses even though instead of on the other hand assuming that even though is a DM which is used to connect two contrasting ideas in two different sentences.

Based on the evidence of using subordinate conjunctions instead of DMs, it is obvious that the writers had problems in linking ideas using logical connections, and therefore, it is incoherent. In other words, as ideas are not logically connected, they fail to produce an effective text. Consequently, it may cause difficulties for the reader in interpreting meaning.

\section{Problems Encountered by the Participants in Applying DMs}

The findings show that from 234 occurrences, there are several problems in the use of DMs found in the participants' argumentative writing (in 118 occurrences). The problems are classified into: non-equivalent exchange (41 occurrences), overuse (32 occurrences), surface logic (27 occurrences), misinterpreted relation (11 occurrences), and mistranslation ( 7 occurrences).

When the origin of the problems is traced from their proficiency and a closer examination is done, it reveals that those who are more competent in writing use a wider range of DMs compared to those who are less competent. They use DMs in an interchangeable manner to avoid repetition of the same DM. Another characteristic of the more competent participants is they tend to use DMs as style enhancer to make their writing more sophisticated. 
On the other hand, participants of a lower proficiency tend to be consistent in using the small cluster of DMs that might be due to the lack of familiarity with other DMs. In terms of relations between sentences, they tend to turn to DMs they are familiar with when they find difficulties in organizing the arguments in their writing, implying that they have problems in organizing their arguments into a coherent text.

\section{Non-Equivalent Exchange Problems}

Non-equivalent exchange is the most common problem found in the participants' compositions, as seen in example (4).

4) Nowadays, information can be obtained from other's writing. Yet, many people complain that writing is not an easy skill.

The example presents the importance and the problem of writing. In combining the sentences, subject uses DM yet. It has been mentioned earlier that yet is the less formal equivalent of nevertheless, which is used to denote unexpected information with negative to positive ordering. The more appropriate DM is however as it is commonly used to introduce a problem.

The non-equivalent problem might stem from how DMs are presented in the textbooks (Zamel, 1983; Field \& Yip, 1992). The list of markers in textbooks offer students a wide range of DMs categorized based on the pragmatic function they carry (e.g. additive, adversative) without semantic and grammatical restriction of each marker. Due to this reason, the students may assume that DMs can be used interchangeably as long as they are under the same pragmatic categorization. The students' assumption seems to be confirmed by the absence of an explicit instruction on how each DM may carry different semantic roles in writing.

\section{Overuse Problems}

The case of overuse happens when the relation between sentences is so obvious that it does not require any DMs, as seen in the excerpt from the subject's composition below. 
5) They are forgiven, religiously; but are they academically being let go? Are there students, *in fact, especially at university level that are unaware of the policy of plagiarism in academic life? (sample 12)

In example (5), the subject uses DM in fact to emphasize the question on whether or not the students at the university level are aware of the consequences in doing plagiarism. The use of DM in fact was unnecessary because the participants already used the word especially, and without DM in fact the sentences are already coherent.

The reasons for the occurrence of the overuse problem can be classified into three kinds. First, it may come from the writers' perception of the readers. There is a possibility that the writer underestimates the readers' knowledge; or, the writer assumes that the readers would understand their writing as they see it. In both assumptions, the writers strongly believe that sentences must be linked with linking words, in this case, DMs. Second, it might be caused by instruction-induced problems, where the instructors and textbooks over emphasize the use of DMs. The latter source may cause the students to have the idea that there is a positive relationship between the quality of writing and the number of DMs used.

\section{Surface Logic Problems}

Surface logic is a type of problem where participants use DMs to impose logic to text, or to bridge the gap among propositions where there is no relation between sentences. Excerpt from the subject's writing below may illustrate the problem.

6) While fluency may in many communicative language course be an initial goal in language teaching, accuracy is achieved to some extent by allowing students to focus on the elements of phonology, grammar, and discourse in their spoken output.

*Therefore, teacher can use task-based language teaching and communicative language teaching as the approaches for teaching language to improve learner accuracy and fluency. *In addition, jigsaw group technique, play a game, or discussion solutions. ${ }^{*}$ However, make sure that your tasks have a linguistic objective and seize the opportunity to help students to perceive and use the building blocks of language. *In addition, don't bore your students to 
death with lifeless, repetition drills, but make the drill as meaningful as possible.

As shown in example (6), there are 4 sentences in one paragraph, all of which begin with a DM. It might be due to misconception about the use of DMs in writing, which is believed to be better. The most glaring example of the surface logic problem is the presence of DM however when the segments it connects have no concessive nor adversative relation. The problem might also result from the shortcomings in logic in the participants' thinking process. The relations between arguments are not organized coherently since it relies on DMs to bridge the logical gap. As a result, the ideas are overtly connected by DMs without the existence of such logical relations. In other words, when they find difficulties in expressing their ideas and argument, they turn to DMs to build "superficial link" (Crewe, 1990). From the participants' side, the reason for employing DMs to impose logic is that their argumentative compositions are written for and to their lecturer to read and assess, so they are written with more DMs to avoid incoherent compositions and lower scores.

\section{Misinterpreted Relation Problems}

Misinterpreted Relation is a problem where the relation represented by the DM does not correspond to the relation that exists between sentences. It can be attributed to the participants' lack of understanding about the logical relationship within the units of discourse. They misinterpret the relation between sentences, thereby misleading the DMs' use. An example for this is as follows.

7) Tasuki (1999) stated that this would indicate that if vocabulary learning is going to be measured by productive use, video is certainly facilitative. ${ }^{*} \boldsymbol{O} \boldsymbol{n}$ the other hand, video will be most efficient if learners are provided with contextualized sentence models.

The first sentence of the example presents the advantage of using video in vocabulary learning. The second sentence is supporting information on the topic "the advantage of video in language learning". The relationship between the first and the second sentence should be additive instead of contrastive. The appropriate marker for the relation is in addition as it describes the characteristic of video in language learning. 


\section{Mistranslation Problems}

Mistranslation problem occurs when the participants transfer their L1 writing practices to their L2 writing. It might be due to the participants' lack of knowledge and instruction in applying certain markers in writing. It also confirms the previous findings in a way that DMs usage has been shown to be closely linked to L1 and culture (Biber \& Finegan, 1988; Altenberg \& Tapper, 1998; Mauranen, 1993). The case of mistranslation is provided in the following example.

8) It is clear that Yuwono and Harborn conclude that motives for entering profession influence how teachers in Indonesia construct their professional development. *On the other side, teachers reward does not, significantly, influence teacher professionalism.

In example (8), after discussing the influence of teachers' motivation in applying a job on their professional development, the subject continues to present somewhat contrast information. In contrasting his/her information, the subject uses the phrase, on the other side, as Indonesian-English word-by-word translation for "di sisi lain". The intended meaning is on the other hand, but due to the lack of lexical repertoire and practice, the subject translates the phrase into on the other side instead of on the other hand.

The findings have shown that EFL learners find problems in using DMs appropriately in compositions. In fact, as a requirement for writing effectively, the use of DMs helps the writer produce a coherent text and get the message across to the readers effectively. However, due to inadequate knowledge of DMs, the absence of DMs does not always necessarily make the text ineffective because in this case the relationship between ideas is implicit. The uses of DMs make it explicit. If the DMs are inappropriately used, sometimes it may disturb the readers in interpreting the meaning or the message, although the meaning may be successfully interpreted. So, such phenomena, basically, indicate the stage where learners are still developing their ability to produce effective text by using DMs.

\section{CONCLUSIONS AND SUGGESTIONS}

Based on the findings, it is concluded that although the participants have shown their awareness of using DMs to build coherent compositions, there are 
still areas that requires improvement in their ability in using DMs appropriately and effectively.

To increase the efficacy of the use of DMs in Indonesian ELT's writing program, the following points should be of more concern especially to English language teachers. English language teachers/lecturers must give explicit instructions about the role of DMs, particularly how the absence, the misuse and overuse of DMs may reduce the quality of writing. The semantic and syntactic restriction of DMs and conjunctions must be addressed to avoid problems. In addition, lecturers should make it clear to the students that DMs do not create but make the relationship between ideas explicit, and thus clearer. Therefore, it is important for the students not to rely too much on DMs in their writing, but how ideas are well and logically connected, and focus on organizing their arguments smoothly and clearly, instead.

\section{REFERENCES}

Altenberg, B., \& Tapper, M. (1998). The use of adverbial connectors in advanced Swedish learners' written English. In S. Granger (Ed.), Learner English on computer (pp. 80-93). New York: Longman.

Biber, D., \& Finegan, E. (1988). Adverbial stance types in English. Discourse Processes, 11(1), 1-34.

Biber, D., Johansson, S., Leech, G., Conrad, S., \& Finegan, E. (1999). Longman grammar of spoken and written English. London: Longman.

Bolton, K., Nelson G., \& Hung, J. (2002). A corpus-based study of connectors in student writing. Research from the International Corpus of English in Hong Kong (ICE-HK). International Journal of Corpus Linguistics, 7(2), 165-182. Retrieved from http://englishteachersplace.com/wpcontent/uploads/2011/09/A-Corpus-based-study-of-connectors-in-studentwriting.pdf.

Celce-Murcia, M. \& Larsen-Freeman, D. (1999). The grammar book (2nd ed.). Michigan: Heinle \& Heinle.

Cho,Y. (1998). Use of connectives in writings by Korean learners of English. (Report No. ED441348). Retrieved from http://eric.ed. gov/ERICWebPortal/recordDetail?accno=ED441348. 
Crewe, W. J. (1990). The illogic of logical Connectives. ELT Journal, 44(4), 316-325.

Field, Y., \& Yip, L. M. O. (1992). A comparison of internal conjunctive cohesion in the English essay writing of Cantonese speakers and native speakers of English. RELC Journal, 25(1), 15-28.

Fraser, B. (1999). What are discourse markers? Journal of Pragmatics, 31(7), 931-952.

Halliday, M.A.K. \& Hasan, R.(1976). Cohesion in English. London: Longman.

Kao, T.Y.\& Chen, L.M. (2011, November). Diagnozing discoursal organization in learner via conjunctive adverbial. Paper presented at the $23^{\text {rd }}$ Conference on Computational Linguistics and Speech Processing, Pittsburgh.

McCarthy, M. (1993). Discourse analysis for language teachers. Cambridge: Cambridge University Press.

Mauranen, A. (1993). Cultural differences in academic rhetoric: A textlinguistic study. Frankfurt: Peter Lang.

Merriam-Webster Dictionary and Thesaurus. (2012). Retrieved from www.merriam-webster.com/.

Müller, S. (2004). Well, you know that type of person: Functions of 'Well' in the speech of American and German students. Journal of Pragmatics, 36(6), 1157-1182.

Narita, M., Sato, C. \& Sugiura, M. (2004). Connector usage in the English essay writing of Japanese EFL learners. Proceedings of the Fourth International Conference on Language Resources and Evaluation, 1171-1174. Retrieved from http://gandalf.aksis.uib.no/non/lrec2004/papers.html

Parrot, M. (2000). Grammar for English language teachers. Cambridge: Cambridge University Press.

Quirk, R, Greenbaum, S., Leech, G., \& Swartvik, J. (1985). A comprehensive grammar of the English language. London: Longman.

Schiffrin, D. (1987). Discourse markers. Cambridge: Cambridge University Press. 
216 TEFLIN Journal, Volume 27, Number 2, July 2016

Tyler, A., \& Bro, J. (1992). Discourse structure in nonnative English discourse. Studies in Second Language Acquisition, 14(1), 71-86.

Zamel, V. (1983). Teaching those missing links in writing. ELT Journal, 37(1), 22-29. 